Малахов Александр Владимирович

аспирант кафедры социальной работы и психологии

Тихоокеанского государственного университета

\section{ВЕРНАКУЛЯР И ЭМАНСИПАЦИЯ: «НАРОДНАЯ» АРХИТЕКТУРА КАК РЕСУРС ДЛЯ СОЦИАЛЬНОГО РАЗВИТИЯ [1]}

Malakhov Alexander Vladimirovich

PhD student, Department of Social Work and Psychology, Pacific National University

\begin{abstract}
Аннотация:
В настоящее время на повестку дня в социальных науках выходит поиск новых ресурсов, обращение к которым позволило бы найти эффрективные ответы на вызовы, возникающие перед обществом. Работая в русле этой тенденции, автор в статье через призму критической теории рассматривает потенциальную роль вернакулярной («народной», «анонимной») архитектуры в решении ключевых проблем современного социума - атомизации, неравенства, маргинализации отдельных групп, экологического кризиса. Обсуждение указанных вопросов подкрепляется обширными полевыми исследованиями «народной» архитектуры, проводимыми автором в разных регионах восточной России в 2018-2019 ге. Текст начинается с обзора текущих дебатов среди теоретиков архитектуры, после чего автор переходит к обсуждению комплексного потенциала вернакуляра, за чем следует описание конкретных шагов, необходимых для актуализации «народной» архитектуры в качестве ресурса социального развития.
\end{abstract}

Ключевые слова:

эмансипация, устойчивость, самоореанизация, сообщество, «народная» архитектура, DIY-архитектура, социальные инновации, социология архитектуры.

\section{VERNACULAR AND EMANCIPATION: VERNACULAR ARCHITECTURE AS A RESOURCE OF SOCIAL DEVELOPMENT [1]}

Nowadays the social science agenda is focusing on the search for new resources to provide effective responses to the challenges faced by the society. The author, working in accordance with this trend and using the lens of critical theory, reviews the potential role of vernacular (folk, anonymous) architecture in solving key problems of contemporary society, such as atomization, inequality, marginalization of certain groups, environmental crisis. The author's discussion of these issues is supported by extensive field research of vernacular architecture, which he carried in various regions of eastern Russia in 2018-2019. The paper begins with a review of the current debate among architectural theorists what leads the author to a discussion of the multidimensional potential of the vernacular, followed by a description of the concrete steps needed to actualize vernacular architecture as a resource for social development.

Keywords: emancipation, sustainability, self-organization, community, vernacular architecture, DIY-architecture, social innovations, sociology of architecture.

На протяжении нескольких десятилетий среди теоретиков архитектуры продолжаются споры об отношениях между архитектурой и обществом, о роли архитектуры в социальных изменениях и этической ответственности архитектора за влияние, оказываемое его работой на окружающий мир. Фракция, которую можно назвать «классицистами», подчеркивает эстетическое измерение объектов и приоритет профессиональной реализации: дело архитекторов - создавать шедевры, обладающие самоценностью; социальный и экономический контексты, как и мотивы заказчика, вторичны или вовсе не должны приниматься в расчет. «Классицистам» оппонируют критические теоретики, считающие, что архитектура не только не автономна от общества со всеми его особенностями и, неизбежно, пороками, но и активно вовлечена в социальные процессы [2]. Архитектура, начиная от общей планировки городов и заканчивая самыми незначительными проектировочными нюансами отдельных зданий, обрамляет и фрормирует социальную жизнь.

Критические теоретики подчеркивают, что исторически архитектура находилась в тесных отношениях с теми, кто пользовался влиянием в обществе, а значит, даже самые выдающиеся объекты, созданные архитекторами, должны были транслировать метапослание заказчика. Как отмечает Г. Бристоль из канадского Центра архитектуры и прав человека, «архитектура всегда была некоторым образом связана с властью, шла ли речь о строительстве домов для Бога (или по крайней мере Его первосвященников) или, ближе к нашему времени, возведении соборов Мамоне и различных формах демонстративного потребления» [3, р. 11]. Забегая вперед, стоит заметить, что такой взгляд при всей его эвристической ценности кажется чрезмерно радикальным, хотя бы потому что исключает абсолютное большинство объектов, построенных когда-либо, из сферы архитектуры.

Более взвешенный подход, когда речь идет о развитии инклюзивной и эмансипирующей архитектуры, как и в случае с другими социальными вызовами, должен не столько критиковать статус-кво, сколько искать возможности обращения его сильных сторон на общую пользу - не 
отрицать благо в имеющемся, но делать это благо достоянием максимального числа людей, а не только привилегированных групп. Можно согласиться с основателем проекта WikiHouse и ведущей фригурой в движении за эгалитаризацию архитектуры А. Парвином, утверждающим, что «наш интерес должен в меньшей степени касаться трансгрессии нормативного и в большей - переизобретения того, что является нормальным... самая радикальная вещь, которую мы можем сделать, - демократизировать ее: спросить, может ли архитектура сегодня, впервые, иметь своими клиентами не 1 \%, а 100 \% [людей]» [4, р. 95]. По мере осознания проблематичного характера текущей ситуации все больше архитекторов начинают поиски альтернатив. Некоторые из них склоняются к необходимости отказа от монологичности профессии и переходу к «постпрофессиональной эре» (Х. Садри), другие предрекают наступление «архитектуры после архитекторов» [5] благодаря развитию искусственного интеллекта и новых технологий, уравнивающих профессионалов и энтузиастов. Пытаясь обобщить дух времени, британский теоретик Т. Краминер констатировал, что использование «знаковых зданий и впечатляющих сооружений для "продажи" городов как глобально [востребованных] и идущих в ногу с рынком, для продажи жилья международным спекулянтам, для добавления лоска солидности и зрелищности откровенно коммерческим начинаниям оставило плохое послевкусие» [6, р. 11]. В ответ на это все больше архитекторов стали обращаться к «расширению участия граждан, к “повседневной” архитектуре, самостоятельному строительству и фоомам архитектуры, которые не были дискредитированы очевидной связью или зависимостью от неолиберализма» [7].

Подобное обращение, однако, не является чем-то новым, если под таковым мы подразумеваем возникновение нового френомена, скорее этот процесс правильнее назвать эмансипацией, в ходе которой голос получают все те, кто воображали, проектировали и возводили дома, не будучи частью профессионального цеха. На вездесущность этих безмолвных строителей и крайне узкую оптику профессиональных архитекторов, упорно не замечающих их существования, обратил внимание Б. Рудофски в 60-х гг. прошлого века [8], но только в последнее время изучение вернакулярной («народной», «анонимной» [9]) архитектуры стало пользоваться широким признанием.

В общем смысле вернакуляр, или «народная» архитектура, - зонтичное понятие, обозначающее любые объекты, построенные без участия профессиональных архитекторов: традиционное жилище аборигенов; сшитая на скорую руку палатка беженцев; временное убежище, сооруженное из подручных средств бездомными; дачный домик небогатой семьи из российской провинции с импровизированным забором из лыж и кроватных спинок; коттедж нового буржуа, принципиально отказавшегося от услуг архитектора, чтобы единолично воплотить детскую мечту о замке. Почти неограниченное многообразие вернакуляра, его непрерывная перестройка и адаптация, отсутствие контроля и фиксированной нормы позволяют рассматривать «народную» архитектуру в качестве гиперобъекта (в терминологии Т. Мортона), подверженного эволюционному отбору. В отличие от фешенебельной «иконической» архитектуры (в этой оценке мы ориентируемся в том числе на работы Л. Склера) вернакуляр не может позволить себе быть избыточным, но в отличие от профессиональной гражданской архитектуры он обязательно отражает чаяния своих создателей, как правило, являющихся его обитателями; «народная» архитектура неизбежно эффрективна и человекоразмерна.

Еще Б. Рудофски отмечал использование в традиционном вернакуляре решений, до которых официальная архитектура дошла только в XX В., но для архитекторов его поколения подобные тезисы звучали в большей степени как дань романтизму, чем руководство к действию. В наше время, когда на повестку дня вышли проблемы экологии и ответственного потребления, обращение к «народной» архитектуре, будь то в виде вернакуляра коренных народов или современной «самодельной» (DIY) архитектуры, стало общим местом. В качестве иллюстрации можно вспомнить вышедший недавно международный сборник с говорящим названием «Устойчивая вернакулярная архитектура: как прошлое может обогатить будущее» [10].

Дома, возводимые людьми для себя, пусть даже в условиях дефицита средств, оказываются более экологичными, используют большую долю вторсырья (а значит, оставляют меньший углеродный след), способствуют поддержанию социальных связей и развитию локальных сообществ (так как помощь в строительстве часто оказывают расширенная семья, соседи, «улица»), имплицитно противостоят «макдональдизации» (культурной унификации) и консюмеризму. Кроме того, поскольку себестоимость вернакуляра оказывается существенно (в некоторых случаях - на порядок) ниже цены «официального» жилья того же уровня комфортности, вернакуляр содействует преодолению крайнего неравенства и достижению социальной справедливости. В этом смысле его можно назвать мультирешением, действующим одновременно в сферах экологии (более низкая нагрузка на окружающая среду), экономики (рециркуляция товаров и сокращение расходов), социальных отношений (поддержание межличностных связей) и культуры (сохранение локальных традиций и региональной самобытности). 
Озвученные утверждения, почерпнутые из анализа мирового опыта, полностью подтверждаются авторскими наблюдениями. В 2018-2019 гг. нашей командой реализовывался проект «Дальневосточные предместья: исследование "народной" архитектуры» [11], в рамках которого мы посетили с экспедициями полторы дюжины городов в девяти регионах восточной части страны, собрали базу из нескольких тысяч «вернакулярных» объектов, провели масштабную полевую работу, применяя смешанные (mixed) методы. Хотя обсуждение результатов проекта задача других публикаций, следует оговорить два тезиса, важных для текущего исследования: во-первых, дальневосточный вернакуляр не только существует в количественном изобилии, но и крайне разнообразен в плане фрорм, стилей, применяемых материалов и планировочных решений; во-вторых, он занимает нишу, которую едва ли может заполнить «официальная» архитектура, а значит, при любых сценариях «народная» архитектура в восточной России не только сохранится, но и продолжит развитие. В среднесрочной перспективе кажется оптимальным, чтобы именно вернакуляр стал базовой фрормой архитектурного освоения неиспользуемых в настоящее время территорий в рамках таких государственных проектов, как «Дальневосточный гектар».

Выглядит почти бесспорным то, что «народная» архитектура обладает значительным потенциалом в качестве ресурса социальных изменений и способна внести свою лепту в создание более инклюзивного и справедливого общества. Какие шаги необходимо предпринять, чтобы актуализировать этот потенциал и ввести вернакуляр «в игру»? Кто должен выступить субъектом или, лучше сказать, катализатором изменений? Признавая актуальность моделей самоорганизации, аутопоэза и симбиоза, развиваемых такими авторами, как М. Деланда [12], мы склонны видеть решение не в ставке на одно действующее лицо (пусть даже коллективное), играющее роль дирижера социальных процессов, а в поиске резонанса между бесчисленными акторами, связями, объектами и микропаттернами, переплетение которых формирует общество. Подобное видение вещей подтверждается специалистами, представляющими самые разные дисциплины, от социологии и экономики до биологии и исследования сложных систем, и если их выводы верны, то дорожные карты, в которых мы нуждаемся, не могут носить иерархический, директивный, механистический характер. Они должны учитывать горизонтальную и сетевую природу общества, не исключающую, впрочем, существования в нем «центров притяжения», или мешворков (meshworks), воспринимать естественные фрлуктуации и проявления спонтанности не в качестве форс-мажоров, требующих экстренного реагирования, а как невычитаемую часть базового сценария [13].

С учетом сказанного имеет смысл уделять приоритетное внимание «мягкой силе», просвещению и культурному воздействию, нормализации и повышению престижности вернакуляра, донесению до широкой аудитории информации о социальных, экономических и экологических преимуществах «народной» архитектуры. Сообщество профессиональных архитекторов может внести свой вклад в «вернакулярное возрождение», предлагая проекты домов и отдельных элементов, освобожденные от ограничений авторских прав (архитектура open source), и организуя общедоступные курсы по азам проектирования и строительства. От государственных структур следует ожидать проявления гибкости в вопросе регулирования частного строительства. Со стороны общественных организаций необходимы лоббирование мер, упрощающих самостоятельное возведение объектов для собственного пользования, и систематическая поддержка частных инициатив на прозрачных условиях. В итоге фундаментальное значение будет иметь способность к самоорганизации: появление ассоциаций «народной» архитектуры, объединяющих энтузиастов и практиков из разных регионов, обменивающихся опытом и популяризирующих вернакуляр в качестве актуального варианта.

Современный мир сталкивается с каскадом кризисов, часть из которых (как экономическое расслоение) хотя и не новы, но приобретают качественно иной масштаб, другие (как нарушение «планетарных границ» и глобальное потепление) носят беспрецедентный характер. Чтобы справиться с ними, необходимо обратиться к творческим, неожиданным решениям, которые в идеале способны быть ответом сразу на несколько проблем. «Народная» архитектура может стать таким решением: актуализированная должным образом, она позволит укреплять сообщества, создавать устойчивые города, сохранять локальные традиции, оставаясь при этом гибкой и открытой экспериментам. Современные технологии, например 3D-печать, и подходы к проектированию и организации труда (open source, эджайл и т. д.) кардинально снижают входной порог, открывая сферу частного строительства для неограниченного числа вовлеченных энтузиастов.

Особым потенциалом «народная» архитектура обладает на территориях восточной части нашей страны, климатические условия, малонаселенность и общая удаленность которой от центра вкупе с имеющейся популярностью вернакуляра делают ее идеальной пилотной площадкой для апробирования новой роли вернакуляра. От Байкала до Камчатки формирующаяся «народная» архитектура способна стать лицом российского Дальнего Востока. 


\section{Ссылки и примечания:}

1. Исследование выполнено при финансовой поддержке РФФИ в рамках научного проекта № 18-012-00537.

2. Yaneva A. Mapping Controversies in Architecture. Chalgrove, 2012. 144 p.

3. Bristol G. The Trouble with Architecture // Neo-Liberalism and the Architecture of the Post Professional Era / ed. by H. Sadri. L., 2018. P. 11-29.

4. Parvin A. Architecture (and the Other $99 \%$ ): Open-Source Architecture and Design Commons // Architectural Design. 2013. Vol. 83, no. 6. P. 90-95. https://doi.org/10.1002/ad.1680.

5. Ingarden K. From Architecture Without Architects to Architecture After Architects // Technical Transactions. 2019. Vol. 8. P. 19-29. https://doi.org/10.4467/2353737XCT.19.078.10857.

6. Kaminer T. The Efficacy of Architecture: Political Contestation and Agency. L., 2017. 218 p.

7. Ibid.

8. Rudofsky B. Architecture Without Architects: A Short Introduction to Non-Pedigreed Architecture. Albuquerque, 1987.157 p.

9. Долгова Е.Д. Эстетика анонимной архитектуры // Вестник СГАСУ. Градостроительство и архитектура. 2016. № 2 (23). C. 91-95. https://doi.org/10.17673/Vestnik.2016.02.17.

10. Sustainable Vernacular Architecture: How the Past Can Enrich the Future / ed. by A. Sayigh. L., 2019.437 p.

11. Дальневосточные предместья: исследование «народной» архитектуры [Электронный pecypc]. URL: http://vernacular.city (дата обращения: 04.02.2020).

12. Деланда М. Новая философия общества. Теория ассамбляжей и социальная сложность. М., 2018.164 с.

13. Лалу Ф. Открывая организации будущего / пер. с англ. В. Кулябиной. М., 2017. 423 с.

Редактор: Тюлюкова Мария Олеговна Переводчик: Кочетова Дарья Андреевна 